\title{
O perfil do bibliotecário que atua na área jurídica: relato de pesquisa ${ }^{1}$
}

\author{
Sofia Galvão Baptista* \\ Edilenice J. Lima Passos** \\ Maria das Graças Soares ${ }^{* * *}$ \\ Luciana Araújo Gomes de Sousa
}

Resumo: A pesquisa teve como objetivo identificar o perfil dos bibliotecários que atuam na área jurídica, no Distrito Federal. Os dados demográficos, formação profissional, ingresso e preparação para atuar na área jurídica, características do emprego, tarefas desempenhadas e salário foram analisados.

Palavras-chave: Acervo jurídico. Especialização de bibliotecários. Bibliotecários jurídicos.

Título: El perfil del bibliotecario que trabaja en el ámbito jurídico: informe de la investigación

\section{Resumem:}

La investigación tuvo como objetivo identificar el perfil de los bibliotecarios que trabajan en el ámbito legal, el Distrito Federal. Los datos demográficos, la formación, la introducción y la preparación para trabajar en el ámbito jurídico, las características de los puestos de trabajo, deberes y salario fueron analizados.

Palabras-clave: Acervo jurídico. Conocimientos de los bibliotecarios. Bibliotecarios jurídicos.

Title: The profile of the librarian who works in the legal area: report of research

\section{Abstract}

This study aims at the identification of the profile of librarians who act in the legal area.

Demographic data, professional education, ingression into and preparation for acting in the legal area, characteristics of the job, tasks and wages are analyzed.

Keywords: Librarian Legal. Expertise. Librarian Profile

\footnotetext{
${ }^{1}$ Trabalho apresentado no "Seminário Nacional de Documentação e Informação Jurídica" Brasília 2007.

* Sofia Galvão Baptista - Professora assistente do Departamento de Ciência da Informação/ UnB. E-mail: sofiag@unb.br. ** Edilenice J. Lima Passos - Bibliotecária da Consultoria Legislativa do Senado Federal. E-mail: edilenic@senado.gov.br

**** Maria das Graças Soares - Aluna do Doutorado de Ciência da Informação e Documentação / UnB. E-mail: mariagsoares@unb.br.

***** Luciana Araújo Gomes de Sousa - Aluna da graduação do curso de Biblioteconomia. E-mail: lucianaG@stf.gov.br
}

Revista Ibero-americana de Ciência da Informação (RICl), v.1 n.2, p. 151-174, jul./dez. 2008 


\section{Introdução}

O trabalho apresenta os resultados preliminares de uma pesquisa que teve como objetivo caracterizar os bibliotecários do Distrito Federal e verificar como eles têm realizado suas atividades na área jurídica.

Os órgãos públicos e outras entidades que lidam com a informação jurídica têm aberto postos de trabalho para os bibliotecários. Isto se deve à necessidade de organizar a complexa e gigantesca massa documental jurídica e produzir instrumentos que possibilitem a recuperação eficiente da informação jurídica.

No estudo realizado sobre quantidade de normas jurídicas editadas no Brasil foi identificado que no período de 05/10/1988 a 05/10/2006:

“ [...] foram editadas no Brasil 3.510.804 (três milhões, quinhentos e dez mil, oitocentos e quatro) normas que regem a vida dos cidadãos brasileiros. Isto representa, em média, 534 normas editadas todos os dias ou 783 normas editadas por dia útil."

(AMARAL et al , 2006, p. 2)

\begin{tabular}{|l|c|}
\hline Tipo de norma jurídica & Quantidade \\
\hline Emendas constitucionais de revisão & 6 \\
\hline Emendas constitucionais & 52 \\
\hline Leis delegadas & 2 \\
\hline Leis complementares & 63 \\
\hline Leis ordinárias & 3.701 \\
\hline Medidas provisórias & 940 \\
\hline Medidas provisórias reeditadas & 5.491 \\
\hline Decretos & 8.947 \\
\hline Decretos sem número & 11.180 \\
\hline Normas federais de hierarquia inferior* & 122.568 \\
\hline Normas estaduais* & 891.112 \\
\hline Normas municipais* & 2.477 .920 \\
\hline
\end{tabular}

Quadro 1: Normas jurídicas produzidas de 1988 a 2006 Fontes: Base de dados de legislação mantida pelo Senado Federal *AMARAL et al (2006)

Se apenas esses dados já causam impacto, soma-se a eles toda a jurisprudência produzida nos tribunais brasileiros, conforme exemplo ilustrativo no quadro 2, e a doutrina que é elaborada para analisar as normas jurídicas. A Bibliografia Brasileira de Direito (BBD) tem arrolado quase 150 mil referências bibliográficas de livros, artigos de periódicos e de jornais. O IUSDATA, base de dados da Universidade de São Paulo, tem compilado mais de 120 mil referências bibliográficas de artigos de periódicos. 


\begin{tabular}{|l|l|c|c|}
\hline \multicolumn{1}{|c|}{ Tribunal } & Ano & Processos distribuídos & Julgamentos \\
\hline Supremo Tribunal Federal & 2006 & 116.216 & 110.284 \\
\hline Superior Tribunal de Justiça & 2006 & 251.020 & 262.343 \\
\hline Superior Tribunal Militar & 2003 & 661 & 662 \\
\hline Tribunal Superior Eleitoral & 2003 & 1.564 & 2.309 \\
\hline Tribunal Superior do Trabalho & 2003 & 159.449 & 97.455 \\
\hline
\end{tabular}

Quadro 2: $\mathrm{N}^{\mathrm{o}}$ de processos distribuídos e julgados

Fontes: Banco Nacional de Dados do Poder Judiciário - http://www.stf.gov.br/bndpj/, Boletim Estatístico do Superior Tribunal de Justiça de 2006.

É inquestionável que o bibliotecário que trabalha nessa área necessita de habilidades e conhecimentos específicos. A presente pesquisa tem, entre outros objetivos, verificar onde e como esses conhecimentos são obtidos.

Inicialmente, foi feito o levantamento com os bibliotecários do Distrito Federal, mas pretende-se ampliar a pesquisa para outras regiões, tentando assim obter o perfil do bibliotecário brasileiro que atua na área jurídica e verificar as dificuldades enfrentadas.

\section{Histórico - o surgimento dos bibliotecários especializados}

A necessidade de especialização dos bibliotecários tem início com o surgimento das bibliotecas especializadas, a elaboração de bibliografias também especializadas e a criação do antigo Instituto Brasileiro de Bibliografia e Documentação (IBBD).

A formação do bibliotecário reflete a necessidade de especialização. No início do século XX, o currículo dos cursos de graduação, sob influência francesa, tinha caráter humanista. Na década de 60 , sob influência americana, passou a oferecer uma formação técnica. $\mathrm{Na}$ década de 70, surgiram os primeiros cursos de pós-graduação e as revistas especializadas. Castro (2000) mostra que a necessidade de erudição (ou generalista) é abandonada pela especialização. Nos dias de hoje, a formação ideal para o bibliotecário seria a combinação da visão francesa (humanista) com a visão americana (técnica), mais o conhecimento acerca dos novos recursos tecnológicos.

Não pode ser esquecido que a Biblioteconomia é uma ciência social aplicada e o bibliotecário necessita também de conhecimento acerca de sua área de atuação. Todavia, no Brasil, não existe nenhum curso de especialização para bibliotecários em áreas especificas de conhecimento. Sendo assim, os bibliotecários neófitos "especializam-se" em função das 
atividades que exercem. Tornam-se, então, bibliotecários médicos se passam a atuar em bibliotecas especializadas em medicina, ou bibliotecários jurídicos se passam a prestar serviços em bibliotecas jurídicas. Eles absorvem no trabalho diário as noções básicas do Direito e seu vocabulário próprio. O mesmo acontece com os bibliotecários que lidam com a informação médica e assim por diante. Alguns profissionais sentem a necessidade de conhecimentos mais profundos da área que atuam ou de educação formal e, para tanto, buscam a dupla formação ao voltar à universidade para graduar-se em Direito ou Medicina, conforme o exemplo dado, a seguir:

Para contextualizar a informação-objeto de seu trabalho, o bibliotecário necessita buscar o conhecimento jurídico, que pode ser adquirido pela educação formal ou não. A compreensão do sistema jurídico nacional, construído sobre os pilares do Estado Democrático de Direito, é condição sem a qual o bibliotecário não consegue dimensionar o alcance dos institutos jurídicos para coordenar os seus conceitos e aplicação. É esse conhecimento que vai instrumentá-lo para definir as estratégias de busca da informação e, com a previsível precisão dos resultados obtidos, garantir a credibilidade de sua relação com o usuário. (LOUREIRO, 2005)

Alguns fatos que consolidaram a importância da documentação jurídica é a existência da Comissão de Documentação e Informação Jurídica, subordinada à Federação Brasileira de Associações de Bibliotecários, Cientistas da Informação e Instituições (FEBAB); os Encontros Nacionais de Informação e Documentação Jurídica (ENIDJ) que está em sua nona edição; a tabela de classificação própria para área: a Classificação Decimal de Direito (CDDir); bases de dados tradicionais, com mais de 30 anos, que controlam a informação jurídica normativa, entre outras tantas.

\subsection{Bibliotecários jurídicos brasileiros}

O bibliotecário jurídico é definido por Passos (2001) como o "profissional que facilita o acesso à informação jurídica de forma ágil e eficiente [...] Seu campo de atuação pode ser bibliotecas jurídicas, universitárias, bibliotecas de órgãos governamentais e bibliotecas de escritórios de advocacia."

Silva (2005, p.24) ao comentar a atuação do bibliotecário jurídico considera que:

[...] o bibliotecário necessita estar atento à sua área de atuação, buscando sempre novos conhecimentos que agreguem valor ao exercício de suas competências através de uma educação continuada no exercício de sua profissão, devendo saber onde encontrar informações jurídicas que atendam às necessidades dos usuários da unidade de informação onde trabalha e definindo os mecanismos de busca mais adequados e atualizados, seja na área médica, da agricultura ou qualquer que seja o seu campo de trabalho. 


\subsubsection{Competências}

As competências do bibliotecário jurídico não foram suficientes estudadas. A American Association of Law Libraries (AALL) procurou estabelecer as competências do bibliotecário jurídico e, para tanto, aprovou um documento que relaciona as sua satividades. Loureiro (2005) a partir da realidade nacional, especifica alguns serviços que podem ser desenvolvidos por bibliotecários jurídicos. No quadro 3, é possível observar uma comparação entre as atribuições relacionadas pela AALL e Loureiro.

\begin{tabular}{|c|c|}
\hline American Association of Law Libraries & Loureiro (2005) \\
\hline $\begin{array}{l}\text { Prover e personalizar serviços de } \\
\text { referência sobre tópicos jurídicos e também em } \\
\text { relevantes tópicos não-jurídicos }\end{array}$ & $\begin{array}{l}\text { Fazer a leitura, selecionar e editar os atos } \\
\text { normativos publicados nos Diários Oficiais e da } \\
\text { Justiça da União, divulgando-os aos usuários no } \\
\text { mesmo dia da publicação, antecipando-se à } \\
\text { demanda. Para desenvolver este serviço com } \\
\text { agilidade é necessário ser assinante do Diário Oficial } \\
\text { Eletrônico publicado pela Imprensa Nacional; } \\
\text { Criar e manter atualizado um sítio da } \\
\text { Biblioteca na Internet e Intranet, no qual devem estar } \\
\text { concentradas as pesquisas de legislação, doutrina e } \\
\text { jurisprudência, bem como o acesso direto a outros } \\
\text { links que contemplam assuntos correlatos e as } \\
\text { normas de documentação da ABNT. Conferir } \\
\text { credibilidade ao site e torná-lo atraente são tarefas } \\
\text { que dependem de criatividade e competência técnica; }\end{array}$ \\
\hline $\begin{array}{l}\text { Avaliar a qualidade, autenticidade, } \\
\text { acuracidade e o custo das fontes tradicionais e } \\
\text { eletrônicas, e mostrar a importância delas para } \\
\text { o cliente }\end{array}$ & $\begin{array}{l}\text { Selecionar sítios da Internet (portais de } \\
\text { acesso gratuito ou pago) que veiculem conteúdos } \\
\text { substanciais para o usuário; criar e disponibilizar os } \\
\text { links de acesso a esses portais na página da } \\
\text { biblioteca; } \\
\text { Selecionar artigos de periódicos que } \\
\text { comentam as atualizações legislativas e encaminhá- } \\
\text { los aos usuários }\end{array}$ \\
\hline $\begin{array}{r}\text { Auxiliar o cliente com as pesquisas } \\
\text { jurídicas utilizando tanto os recursos impressos }\end{array}$ & $\begin{array}{c}\text { Disponibilizar um sistema } \\
\text { recuperação da informação, que } \\
\text { de }\end{array}$ \\
\hline
\end{tabular}




\begin{tabular}{|c|c|}
\hline quanto eletrônicos & $\begin{array}{l}\text { independência e satisfação do usuário; } \\
\text { Criar serviços que promovam o } \\
\text { detalhamento virtual do acervo, selecionando } \\
\text { periodicamente um de seus itens para desvelar o seu } \\
\text { conteúdo, apresentando-o como sugestão de leitura. } \\
\text { Na impossibilidade de flanar freqüentemente pelo } \\
\text { acervo físico da Biblioteca, este é um serviço de } \\
\text { grande utilidade para os seus usuários remotos. }\end{array}$ \\
\hline $\begin{array}{l}\text { Auxiliar aqueles que não são } \\
\text { advogados no acesso às leis dentro das } \\
\text { diretrizes da American Bar Association's } \\
\text { Model Code of Professional Conduct e outros } \\
\text { códigos aplicáveis }\end{array}$ & \\
\hline $\begin{array}{l}\text { Agregar conteúdo a variedade de } \\
\text { recursos e sintetizar a informação para criar } \\
\text { produtos personalizados para o cliente }\end{array}$ & $\begin{array}{l}\text { Sempre que possível, complementar uma } \\
\text { informação com outra, agregando valor ao serviço. } \\
\text { Por exemplo, ao informar a publicação de uma nova } \\
\text { lei que altera dispositivo da CLT, informar também a } \\
\text { redação anterior da norma, conferindo agilidade à } \\
\text { pesquisa do usuário; } \\
\text { Criar links para formação e comunicação de } \\
\text { grupos de estudos jurídicos. }\end{array}$ \\
\hline $\begin{array}{l}\text { Criar instrumentos de pesquisa e } \\
\text { bibliográficos em Direito e tópicos correlatos }\end{array}$ & $\begin{array}{l}\text { Manter atualizado o catálogo de endereços } \\
\text { eletrônicos de juízes, servidores e outros usuários } \\
\text { para assegurar a disseminação da informação. }\end{array}$ \\
\hline $\begin{array}{l}\text { Monitorar as tendências em áreas } \\
\text { específicas do Direito }\end{array}$ & $\begin{array}{l}\text { Promover a divulgação da produção } \\
\text { intelectual interna do Órgão, dando destaque à } \\
\text { iniciativa e estimulando a geração de novos } \\
\text { conhecimentos. }\end{array}$ \\
\hline
\end{tabular}

Quadro 3 - Competências do bibliotecário jurídico

O bibliotecário jurídico brasileiro é um ilustre desconhecido. Foram localizadas poucas pesquisas sobre o seu perfil. Os estudos de Ohira et al (1998) e Passos (2004) procuraram traçar este perfil a partir de sua produção bibliográfica. Alguns pontos foram identificados:

a) O principal canal de divulgação de seus trabalhos é a comunicações em eventos científicos; 
b) A maioria dos trabalhos tem autoria individual;

c) $98 \%$ dos trabalhos estudados foram escritos em português;

d) Em relação ao sexo dos autores, o feminino é predominante;

e) $81 \%$ dos autores estudados publicaram um único trabalho;

f) São bastante variados os temas abordados pelos autores. Passos (2004) identificou apenas um autor que tem claramente delineada uma linha de pesquisa.

Mesmo com essas duas pesquisas, o bibliotecário jurídico brasileiro permanece desconhecido. Não há estatísticas sobre o número de bibliotecários que trabalham na área; quantos possuem dupla formação; quantos possuem cursos de pós-graduação; quais são os locais onde atuam; quais as atividades que desenvolvem e sua faixa salarial.

\subsubsection{Perfil e salários}

Em relação ao salário, Silva (2005, p.24) aponta que os bibliotecários que atuam nessa área são os profissionais que recebem melhores salários: "Em termos financeiros, a atuação como bibliotecário jurídico demonstra ser uma das áreas mais rentáveis, como pode ser verificado em muitos concursos públicos realizados nos últimos anos".

Essa situação parece ser similar ao que acontece nos Estados Unidos, onde os bibliotecários jurídicos recebem bons salários. A cada dois anos, a AALL realiza uma pesquisa sobre salários. Na pesquisa de 2003, foi revelado que o salário médio anual varia em torno de U\$ 50,000 a U\$ 52,000. Se ocupar o cargo de chefia o salário poderia chegar a U\$ 75,000 (GRANT \& ACOSTA, 2004, p. 5).

Em outra pesquisa, os bibliotecários norte-americanos mostraram descontentamento em relação aos salários, pois consideram que outros profissionais com o mesmo nível de educação recebem salários mais altos. (GRANT \& ACOSTA, 2004, p. 5).

No Brasil, não é possível determinar se os bibliotecários atuam na área jurídica estão satisfeitos com os seus rendimentos, devido à inexistência de pesquisas.

\subsubsection{Educação continuada e as exigências do mercado}

O recém-formado enfrenta muitas dificuldades, pois é uma área difícil para quem não tem familiaridade com a linguagem, tipos de documentos e outras particularidades da informação jurídica. 
Para Anderson (1998) o atendimento / resposta da questão jurídica é um dos conflitos encontrados na comunicação usuário / serviço de referência. O usuário utiliza uma linguagem especializada nem sempre fácil de ser decodificada. $\mathrm{O}$ autor afirma que esta comunicação ou relacionamento colaborativo deve ser trabalhado pelo bibliotecário que está no atendimento.

A necessidade de especialização, para melhor atuação nesta área, é amplamente reconhecida. Porém, têm-se indícios de que nem sempre a educação continuada é escolhida como forma de se preparar e, para diminuir as dificuldades da área.

Para Valentim (2002, p.122):

A educação continuada é base para uma profissão consolidada, assim como é base para um profissional competente. Para a profissão, porque é através dela que construímos seu corpus teórico-prático e, para o profissional, porque é através dela que aprendemos a aplicar esse mesmo corpus teórico-prático.

Em outro trecho Valentim (2002, p. 130) comenta até onde vai a responsabilidade da escola e onde começa a responsabilidade do profissional: "[...] manter essas competências e habilidades profissionais, após a sua saída da escola, é papel do próprio profissional. A autora afirma que existe a necessidade de se ter uma postura investigadora e crítica".

Tendo em vista todas as mudanças resultantes das premissas da sociedade da informação, da tecnologia e de outros fatores, o bibliotecário da área jurídica ou de qualquer outra área deve estar atento e preparado para agir de modo a transformar todas essas mudanças numa oportunidade de melhorar sua atuação.

O mercado de trabalho em geral sofreu mudanças, o perfil exigido modificou-se quanto à qualificação necessária, Paiva $(2004$, p. 2) comenta:

\begin{abstract}
Capacidade de pensamento abstrato ou de prospecção, bem como as próprias qualidades pessoais, se tornou valor de troca explícito - o mundo de hoje compra experiência contemporânea vivida, habilidade no relacionamento pessoal, capacidade de trabalho em grupo. Mesmo altamente qualificados, segmentos etários com mais idade são facilmente descartados, por vezes, pela simples suspeita de que não possam adquirir novos conhecimentos e se adaptar ao uso de tecnologias modernas ou por se manterem no meio profissional como memória de uma época quando existia maior proteção social com conseqüente atuação potencialmente disruptiva em relação à nova ordem.
\end{abstract}

A tecnologia modificou o trabalho do bibliotecário quanto ao volume e natureza das informações que circulam em vários espaços informacionais, Morigi e Silva (2005, p.3) comentam:

As tecnologias de informação e comunicação possibilitam a criação, circulação e armazenamento de uma grande quantidade de informações, mas elas não possuem valor por si mesmas. São necessários profissionais especializados para lidar com essas tecnologias para capacitar os cidadãos no uso de computadores e dos serviços 
oferecidos pelas redes de comunicação. Assim, organizar a informação na Internet, desenvolver sistemas compreensíveis aos usuários de informação, etc. é onde, pelo menos teoricamente, abre-se espaço para o novo bibliotecário, inserido na sociedade pós-industrial.

A educação continuada é uma solução para os bibliotecários enfrentarem as mudanças no mercado. A área jurídica, assim como outra, necessita de profissionais preparados, ativos e tecnologicamente aptos, para atuar como facilitadores entre os repositórios de informação e os usuários. No entanto, há indícios de que a prática da educação continuada não é uma constante entre os profissionais da área.

Crespo et al (2006, p.8) comentam os entraves da educação continuada:

O desinteresse do profissional em se qualificar, em aprender novas técnicas, deve-se a fatores diversos, tais como: distância geográfica e falta de tempo, que muitas vezes pode ser gerada pelo acúmulo de trabalho, escassez de recursos, de incentivo institucional ou financeiro. Além disso, há pouca variedade de temas abordados e percebe-se uma tendência a centralizar esses eventos em grandes centros urbanos em detrimento às localidades mais afastadas.

No caso específico do bibliotecário jurídico brasileiro, a educação continuada não pode ser buscada nos bancos das universidades, pois não existe nenhum curso de especialização nessa área. A opção seria fazer o curso de graduação em Direito. Esforço que, aparentemente, muitos bibliotecários não se dispõem a enfrentar. Entretanto, há a opção de cursos de curta duração oferecidos por associações de bibliotecários ou grupos jurídicos. Paula (2005, p. 35) informa que o "SENAC São Paulo, por exemplo, oferece um curso onde o participante aprende noções de Documentação e Informação Jurídica, visando o aperfeiçoamento da prestação de serviço e o desenvolvimento de produtos informativos inovados, com melhor qualidade de resultados na satisfação do cliente."

Outra possibilidade é freqüentar os eventos especializados. Felizmente, nesse quesito os bibliotecários jurídicos têm várias opções, pois são realizados eventos já tradicionais na área. Segundo Passos (2004, p.189), o Encontro Nacional de Informação e Documentação Jurídica (ENIDJ) é o grande evento científico desta área, tendo até o presente momento, sete edições com periodicidade irregular (Quadro 4):

\begin{tabular}{|c|l|c|}
\hline Evento & \multicolumn{1}{|c|}{ Local } & Ano \\
\hline $1^{\mathbf{o}}$ & Curitiba & 1984 \\
\hline $2^{\mathbf{o}}$ & Brasília & 1986 \\
\hline $3^{\mathbf{o}}$ & São Paulo & 1988 \\
\hline $4^{\mathbf{o}}$ & São Paulo & 1992 \\
\hline $5^{\mathbf{o}}$ & Porto Alegre & 1996 \\
\hline $6^{\mathbf{0}}$ & Florianópolis & 1998 \\
\hline $7^{\mathbf{0}}$ & Porto Alegre & 2000 \\
\hline
\end{tabular}

Quadro 4: Encontro Nacional de Informação e Documentação Jurídica 
Miranda e Solino (2006) ressaltam que a educação continuada pode ser praticada de várias formas, tais como: participação em seminários, congressos, conferências ou ciclos de debates; leitura de trabalhos de congressos publicados em anais, livros e periódicos especializados nacionais e estrangeiros; cursos de características e duração diversificada, teóricos ou práticos, bem como cursos de educação à distância; programas de pós-graduação; estudos individuais e em grupos com colegas; visitas técnicas e participação em grupos de discussão

Existe ainda a possibilidade de cursos à distância. Para Dimário et al (2006), o bibliotecário deve estar apto a dominar as tecnologias e redes interativas que possibilitam o acesso rápido à informação, tanto para mediação da informação para o usuário quanto para sua educação continuada. A proposta de um modelo de curso à distância sobre normalização de trabalhos científicos para bibliotecários seguirá um caráter interdisciplinar, dinâmico e de duração. Os autores ressaltam que os ambientes de aprendizagem virtual, que dão suporte à educação continuada à distância são baseados em ferramentas de comunicação que possibilitam a construção colaborativa de conhecimentos e uma avaliação formativa baseada em desempenho.

Com base na análise das ferramentas de comunicação utilizadas dos cursos de educação à distância nas Universidades Paulistas (USP, UNESP e INUCAMP) Dimário et al (2006) destacam algumas características que deverão ser observadas pelos coordenadores de cursos no momento da escolha dessas ferramentas para gerenciar o processo de aprendizagem virtual.

\section{Metodologia empregada na pesquisa com bibliotecários da área jurídica}

Foi realizada uma pesquisa de natureza descritiva quantitativa, com o objetivo levantar dados sobre faixa etária, sexo, local, residência, graduação, tempo de formado, preparação para ingresso (cursos); forma de ingresso; tarefas desempenhadas, faixa salarial dos bibliotecários jurídicos que atuam no Distrito Federal.

O levantamento dos dados foi realizado com o envio de questionário, composto por 18 questões abertas e fechadas.

O questionário foi enviado, por correio eletrônico, para todos os bibliotecários cadastrados no sistema de mala direta do Conselho Regional de Biblioteconomia (CRB1) e 
para os participantes da lista discussão "Infolegis", por ser uma lista discussão que reúne bibliotecários jurídicos e é especializada em divulgar informações jurídicas.

Os resultados foram analisados pelo SPSS (Statistical Package for Social Sciences) versão 10.0 .

\section{Análise dos resultados}

As questões procuraram traçar o perfil do bibliotecário jurídico que atua no Distrito Federal. Foram levantados dados demográficos, a forma de ingresso na área, tipo de biblioteca de atuação, educação continuada, as tarefas realizadas, faixa salarial e dificuldades enfrentadas para o exercício da profissão. Foram recebidas 54 respostas. Os resultados obtidos e sua análise são mostrados nos próximos tópicos.

\subsection{Dados demográficos}

A intenção foi identificar e caracterizar o respondente em relação ao gênero, faixa etária, forma de ingresso na carreira.

\subsubsection{Sexo}

A maioria dos respondentes $(83,3 \%)$ é do sexo feminino. Esse resultado é coerente com outras pesquisas que mostra que a profissão do bibliotecário é considerada uma profissão feminina. Esse resultado é revelado em outras pesquisas sobre o bibliotecário, tais como: Baptista (1998) e Cunha et al. (2004).

\subsubsection{Faixa etária}

Sobre a faixa etária, percebeu-se uma concentração de bibliotecários na faixa de 41 a 45 anos. Os demais ficaram dispersos em outras faixas, como pode ser visto na tabela abaixo: 


\section{Tabela 1: Faixa etária}

\begin{tabular}{l|c|c}
\hline Faixa etária & $\mathbf{N}^{\mathbf{0}}$ de respondentes & Porcentagem \\
\hline \hline 18 a 25 anos & 7 & $13 \%$ \\
\hline 26 a 30 anos & 7 & $13 \%$ \\
\hline 31 a 35 anos & 6 & $11,1 \%$ \\
\hline 36 a 40 anos & 6 & $11,1 \%$ \\
\hline 41 a 45 anos & 14 & $25,9 \%$ \\
\hline 46 a 50 anos & 8 & $14,8 \%$ \\
\hline Acima de 51 anos & 5 & $9,3 \%$ \\
\hline Não respondeu & 1 & $1,9 \%$ \\
\hline Total & $\mathbf{5 4}$ & $\mathbf{1 0 0 \%}$ \\
\hline
\end{tabular}

\subsubsection{Forma de ingresso}

A maior parte dos respondentes ingressou na carreira por meio de concurso, como está demonstrado na tabela 2 .

Tabela 2: Forma de ingresso

\begin{tabular}{l|c|c}
\hline Forma de ingresso & $\mathbf{N}^{\mathbf{0}}$ de respondentes & Porcentagem \\
\hline \hline Concurso & 39 & $72,2 \%$ \\
\hline Entrevistas & 13 & $24,1 \%$ \\
\hline Outros & 1 & $1,9 \%$ \\
\hline Não respondeu & 1 & $1,9 \%$ \\
\hline \hline Total & $\mathbf{5 4}$ & $\mathbf{1 0 0 \%}$
\end{tabular}

\subsection{Formação}

Mais da metade dos respondentes $(59,3 \%)$ tem mais de 10 anos de formado:

Tabela 3: Tempo de formatura

\begin{tabular}{l|c|c}
\hline Tempo de formatura & $\mathbf{N}^{\mathbf{0}}$ de respondentes & Porcentagem \\
\hline \hline Menos de 1 ano & 1 & $1,9 \%$ \\
\hline 1 a 3 anos & 11 & $20,4 \%$ \\
\hline 4 a 6 anos & 5 & $9,3 \%$ \\
\hline 7 a 10 anos & 5 & $9,3 \%$ \\
\hline Mais de 10 anos & 32 & $59,3 \%$ \\
\hline Total & $\mathbf{5 4}$ & $\mathbf{1 0 0 \%}$ \\
\hline
\end{tabular}

Quanto à área de formação 68,5\% é formado somente em Biblioteconomia, 27,8\% é formado em Biblioteconomia e possuem outra graduação e, entre esses, 20 (37\%) fizeram curso de pós-graduação. Dois respondentes são formados somente em Direito. 


\subsubsection{Universidade em que se formou}

A maior parte dos respondentes é formada em Biblioteconomia pela Universidade de Brasília.

\subsubsection{Educação continuada}

Ao serem indagados se haviam frequientado cursos para adquirirem conhecimentos específicos para atuar na área jurídica, $65 \%$ dos respondentes informaram que não fizeram cursos específicos.

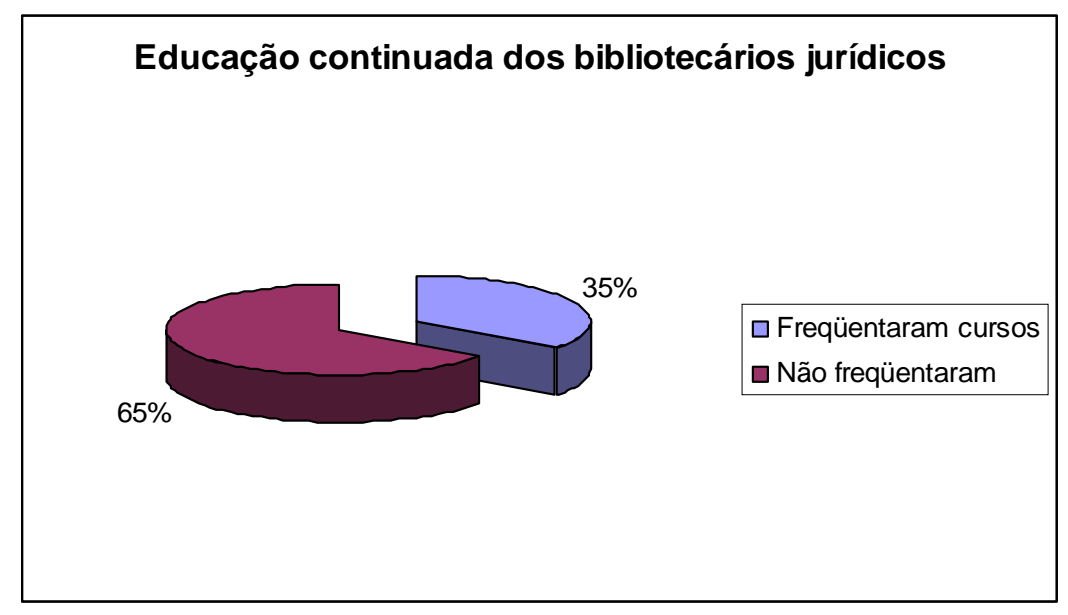

Figura 1 - Bibliotecários que freqüentaram cursos específicos para atuar em bibliotecas jurídicas.

Esses dados demonstram a percepção inicial de que o bibliotecário jurídico especializa-se em função da biblioteca onde desempenha sua profissão. O enfrentamento e as soluções das tarefas diáriasproporcionam, ao longo do tempo, o conhecimento básico necessário para o exercício da profissão. A literatura sobre formação do bibliotecário mostra que os bibliotecários investem pouco em educação continuada e que a escola forma um profissional generalista. A responsabilidade de se aperfeiçoar é pessoal de cada bibliotecário (Valentim, 2002).

De acordo com os respondentes que já fizeram algum curso para atuar na área jurídica, o curso "Noções básicas de Direito" foi o mais apontado e o curso "Organização de escritórios de advocacia" foi o menos apontado. 
Na última pergunta do questionário havia uma questão aberta sobre a área de atuação dos bibliotecários jurídicos. Foram selecionados três depoimentos dos respondentes que refletem a visão deles sobre o assunto:

"Muitos profissionais sentem dificuldades devido à falta de formação adequada para tratar a informação jurídica, ou nunca ter estudado Direito. Consideram difícil o início do trabalho com esse tipo de informação, por ser o Direito uma área muito complexa."

"O conhecimento da área jurídica é fundamental para um bom desempenho profissional nessa área. Alguns bibliotecários estão em busca de uma graduação em Direito adquirir conhecimentos mais específicos".

"Faltam cursos de pós-graduação voltados para os bibliotecários jurídicos, cursos de atualização / especialização e treinamentos em Brasília."

Ao serem questionados sobre o curso preparatório para a área jurídica, apenas 16 respondentes deram essa informação. Os dados ficaram pulverizados entre associação de bibliotecários, grupo jurídico, universidade, CADÊJUR ${ }^{3}$. Metade dos respondentes indicou que foram outras instituições, mas não deram detalhes.

A necessidade de uso de novas tecnologias também requer investimentos na educação continuada, como diz Morigi e Silva (2005 p.3): "A tecnologia modificou o trabalho do bibliotecário quanto ao volume e natureza das informações". No caso do bibliotecário jurídico essa afirmação é muito acertada, porque o profissional precisa ter conhecimentos básicos sobre a área jurídica; carece de informações sobre quais são e como utilizar as várias bases de dados existentes; deve conhecer as fontes de informação tradicionais e novas que surgem com muita rapidez; e, acima de tudo, ser um fornecedor de informação, criando bases de dados ou sítios na Internet ou implantado serviços virtuais de respostas às questões dos usuários.

Em relação a esta questão, ficou-se sem resposta para ilustrar como esses profissionais de uma área especializada estão se qualificando e atualizando seus conhecimentos para atender as demandas recebidas. Não foi esclarecida, também, a dúvida se esses profissionais estão respondendo de maneira correta as questões apresentadas por seus usuários.

A partir das respostas dadas à questão sobre as dificuldades para atuar na área jurídica, ficou evidente a necessidade de curso de especialização para atuar na área jurídica, pois $72 \%$ dos entrevistados apontaram a inexistência de curso de especialização como uma das dificuldades para atuarem na área.

\footnotetext{
${ }^{3}$ Cadêjur é uma empresa que oferece cursos de pesquisa jurídica na Internet. 
Especificamente, $72 \%$ dos respondentes afirmaram ter dificuldade para entender a linguagem jurídica e $61 \%$ se ressentem da falta de noções básicas de Direito. Entre os entrevistados, apenas $17 \%$ tinham feito curso sobre "Noções básicas do Direito".

\section{Tabela 4: Dificuldades para atuarem na área jurídica}

\begin{tabular}{l|c|c}
\hline Dificuldades para atuarem na área jurídica & Sim & Não \\
\hline \hline Falta de curso de especialização na área & $72 \%$ & $28 \%$ \\
\hline Dificuldade para entender a linguagem jurídica & $72 \%$ & $28 \%$ \\
\hline Falta de noções básicas sobre o Direito & $61 \%$ & $39 \%$ \\
\hline Dificuldade para entender o processo legislativo & $46 \%$ & $54 \%$ \\
\hline Desconhecimento das fontes de informação jurídica & $33 \%$ & $67 \%$ \\
\hline Falta de bases de dados que reúna a legislação estadual/ distrital/ municipal & $29 \%$ & $71 \%$ \\
\hline Desconhecimento de idiomas estrangeiros & $28 \%$ & $72 \%$ \\
\hline Dificuldade para entender a organização judiciária & $26 \%$ & $74 \%$ \\
\hline Dificuldade nas pesquisas em bases dados jurídicas & $24 \%$ & $76 \%$ \\
\hline
\end{tabular}

$\mathrm{Na}$ pergunta aberta do questionário, foi possível identificar que os bibliotecários jurídicos estão satisfeitos com a infra-estrutura disponível nos locais de trabalho, porém existem algumas dificuldades enfrentadas para exercer a profissão. Um dos respondentes esclareceu:

"Para quem trabalha com legislação, é um desafio diário buscar informações atualizadas; a linguagem é muito rebuscada; a legislação sofre constantes alterações, falta ordenamento das leis, o que dificulta a recuperação."

\subsection{Características do emprego}

A seguir, são comentados os dados levantados sobre o tipo de biblioteca, as tarefas realizadas e a faixa salarial.

\subsubsection{Tipo de biblioteca}

Os resultados, mostrados na tabela 5, ilustram que o grande empregador dos bibliotecários jurídicos é a Administração Pública. 
Tabela 5: Tipo de biblioteca onde exercem a função

\begin{tabular}{l|c|c|}
\hline Tipo de Biblioteca & $\mathbf{N}^{\mathbf{0}}$ de respondentes & Porcentagem \\
\hline \hline Poder Legislativo & 13 & $24,1 \%$ \\
\hline Poder Judiciário & 20 & $37 \%$ \\
\hline Poder Executivo & 8 & $14,8 \%$ \\
\hline Universidade & 1 & $1,9 \%$ \\
\hline Escritórios de advocacia & 6 & $11,1 \%$ \\
\hline Outros & 6 & $11,1 \%$ \\
\hline \hline Total & $\mathbf{5 4}$ & $\mathbf{1 0 0 \%}$ \\
\hline
\end{tabular}

Confrontando esses dados com as informações sobre a forma de ingresso (item 4.1.3), verificou-se que o concurso público é a forma de ingresso mais utilizada. A maioria dos respondentes atua em bibliotecas de órgãos públicos, onde há a exigência constitucional de concurso.

Com essas informações também ficou esclarecido porque o curso "organização de escritórios de advocacia" foi o menos freqüentado pelos respondentes, esse nicho de mercado é o menos ocupado por aqueles que responderam o questionário.

\subsubsection{Tarefas}

A tarefa mais exercida pelos respondentes é pesquisa $(75,9 \%)$, catalogação $(53,7 \%)$ e acompanhamento de legislação $(48,1 \%)$.

\section{Tabela 6 - Tarefas exercidas}

\begin{tabular}{l|l|l}
\hline Tarefas & \multicolumn{1}{|c|}{ sim } & não \\
\hline \hline Pesquisa & $41(75,9 \%)$ & $13(24,1 \%)$ \\
\hline Catalogação & $29(53,7 \%)$ & $25(46,3 \%)$ \\
\hline Acompanhamento legislação & $26(48,1 \%)$ & $25(51,9 \%)$ \\
\hline Classificação & $23(42,6 \%)$ & $31(57,4 \%)$ \\
\hline $\begin{array}{l}\text { Coleta e organização de normas } \\
\text { internas }\end{array}$ & $21(38,9 \%)$ & $33(61,1 \%)$ \\
\hline $\begin{array}{l}\text { Disseminação Seletiva da } \\
\text { Informação }\end{array}$ & $21(38,9 \%)$ & $33(61,1 \%)$ \\
\hline Desenvolvimento de coleções & $20(37 \%)$ & $34(63 \%)$ \\
\hline Manutenção serviço Internet & $12(22,7 \%)$ & $42(77,8 \%)$ \\
\hline Acompanhamento de jurisprudência & $8(14,8 \%)$ & $46(85,2 \%)$ \\
\hline Outras tarefas & $(6) 11,9 \%$ & $48(88,9 \%)$ \\
\hline
\end{tabular}




\subsubsection{Salário}

Confirmando a percepção de Silva (2005, p.24) sobre os salários dos profissionais dessa área, percebeu-se uma concentração de $52 \%$ de bibliotecários recebendo de R $\$ 5.000$ reais a $\mathrm{R} \$ 10.000$ e $24,1 \%$ acima de $\mathrm{R} \$ 10.000$ reais.

\section{Tabela 7: Faixa salarial}

\begin{tabular}{|c|c|c|}
\hline Faixa salarial & $\mathbf{N}^{0}$ de respondentes & Porcentagem \\
\hline Menos de $\mathrm{R} \$ 1.000,00$ & 1 & $1,9 \%$ \\
\hline De $\mathrm{R} \$ 1.001,00$ a $\mathrm{R} \$ 2.000,00$ & 4 & $7,4 \%$ \\
\hline De $\mathrm{R} \$ 2.001,00$ a $\mathrm{R} \$ 3.000,00$ & 10 & $18,5 \%$ \\
\hline De $\mathrm{R} \$ 3.001,00$ a $\mathrm{R} \$ 4.000,00$ & 4 & $7,4 \%$ \\
\hline De $\mathrm{R} \$ 4.001,00$ a $\mathrm{R} \$ 5.000,00$ & 7 & $13 \%$ \\
\hline De $\mathrm{R} \$ 5.001,00$ a R $\$ 6.000,00$ & 7 & $13 \%$ \\
\hline De $\mathrm{R} \$ 6.001,00$ a $\mathrm{R} \$ 7.000,00$ & 2 & $3,7 \%$ \\
\hline De $R \$ 7.001,00$ a $R \$ 8.000,00$ & 3 & $5,6 \%$ \\
\hline De $\mathrm{R} \$ 8.001,00$ a $\mathrm{R} \$ 9.000,00$ & 1 & $1,9 \%$ \\
\hline De $\mathrm{R} \$ 9.001,00$ a $\mathrm{R} \$ 10.000,00$ & 2 & $3,7 \%$ \\
\hline Acima de $\mathrm{R} \$ 10.000,00$ & 13 & 24,1 \\
\hline Total & 54 & $100 \%$ \\
\hline
\end{tabular}

Tabela 8 - Faixa salarial por tipo de instituição

\begin{tabular}{|c|c|c|c|c|c|c|c|c|c|c|c|c|}
\hline Salário & menos de & $\begin{array}{c}1001 \mathrm{a} \\
2000\end{array}$ & $\begin{array}{c}2001 \mathrm{a} \\
3000\end{array}$ & $3001 \mathrm{a}$ & $\begin{array}{c}4001 \mathrm{a} \\
5000\end{array}$ & $\begin{array}{c}5001 \\
\text { a } 6000\end{array}$ & $\begin{array}{c}6001 \mathrm{a} \\
7000\end{array}$ & $\begin{array}{c}7001 \mathrm{a} \\
8000\end{array}$ & $\begin{array}{c}8001 \text { a } \\
9000\end{array}$ & $\begin{array}{l}9001 \mathrm{a} \\
10000\end{array}$ & $\begin{array}{c}\text { acima } \\
\text { de }\end{array}$ & \\
\hline & mil rea1s & reais & reais & 4000 rea1s & reais & reais & reais & reais & reais & reais & 10000 & \\
\hline
\end{tabular}

\begin{tabular}{|c|c|c|c|c|c|c|c|c|c|c|c|c|c|}
\hline \multirow{7}{*}{$\begin{array}{c}\text { Tipo de } \\
\text { biblioteca }\end{array}$} & legislativo & & 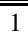 & & & & & 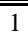 & 2 & & & 9 & 13 \\
\hline & judiciário & & & & 1 & 6 & 4 & 1 & 1 & 1 & 2 & 4 & 20 \\
\hline & executivo & 1 & 3 & 2 & 1 & & 1 & & & & & & 8 \\
\hline & universidade & & & & & & 1 & & & & & & 1 \\
\hline & escritório de & & & 4 & 1 & 1 & & & & & & & 6 \\
\hline & advocacia & & & & & & & & & & & & \\
\hline & outros & & & 4 & 1 & & 1 & & & & & & 6 \\
\hline Total & & 1 & 4 & 10 & 4 & 7 & 7 & 2 & 3 & 1 & 2 & 13 & 54 \\
\hline
\end{tabular}

Neste cruzamento entre a variável "local de trabalho" e a variável "faixa salarial", foi visto que os salários mais baixos são os oferecidos pelo poder executivo e pelos escritórios de advocacia. Por sua vez, os mais altos são recebidos pelos bibliotecários jurídicos empregados pelo poder legislativo. 
Uma das respostas à pergunta aberta sobre salário indicou que o objetivo de alguns bibliotecários jurídicos é alcançar a faixa salarial paga pelo poder legislativo. De acordo com um dos depoimentos, essa disposição fica evidente:

“A proximidade com o Legislativo e a atração exercida pela remuneração oferecida causa certa acomodação no local de trabalho, já que sempre se espera conseguir passar em concurso para aquele setor.".

\section{Tabela 9 - tempo de formado versus salário}

\begin{tabular}{|c|c|c|c|c|c|c|c|c|c|c|c|c|}
\hline Salário & $\begin{array}{c}\text { menos } \\
\text { de mil } \\
\text { reais }\end{array}$ & $\begin{array}{c}\text { de } 1001 \\
\text { a } 2000 \\
\text { reais }\end{array}$ & $\begin{array}{c}2001 \text { a } \\
3000 \\
\text { reais }\end{array}$ & $\begin{array}{c}3001 \text { a } \\
4000 \\
\text { reais }\end{array}$ & $\begin{array}{c}4001 \text { a } \\
5000 \\
\text { reais }\end{array}$ & $\begin{array}{c}5001 \text { a } \\
6000 \\
\text { reais }\end{array}$ & $\begin{array}{c}6001 \mathrm{a} \\
7000 \\
\text { reais }\end{array}$ & $\begin{array}{c}7001 \text { a } \\
8000 \\
\text { reais }\end{array}$ & $\begin{array}{c}8001 \text { a } \\
9000 \\
\text { reais }\end{array}$ & $\begin{array}{c}9001 \mathrm{a} \\
10000 \\
\text { reais }\end{array}$ & $\begin{array}{c}\text { acima } \\
\text { de } \\
10000\end{array}$ & Total \\
\hline tempo de menos de 1 ano & 1 & & & & & & & & & & & 1 \\
\hline \multicolumn{13}{|l|}{ formado } \\
\hline de 1 a 3 anos & & 2 & 3 & 1 & 4 & 1 & & & & & & 11 \\
\hline de 4 a 6 anos & & 1 & 2 & & & 2 & & & & & & 5 \\
\hline 7 a 10 anos & & & 3 & 1 & & & 1 & & & & & 5 \\
\hline mais de 10 anos & & 1 & 2 & 2 & 3 & 4 & 1 & 3 & 1 & 2 & 13 & 32 \\
\hline Total & 1 & 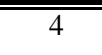 & 10 & 4 & 7 & 7 & 2 & 3 & 1 & 2 & 13 & 54 \\
\hline
\end{tabular}

Foi visto que, no cruzamento da variável "tempo de formado" com a variável "salário", 41 \% dos bibliotecários, com mais de 10 anos de tempo de formado, estão na faixa salarial acima de $\mathrm{R} \$ 10000,00$ reais.

\subsection{Comentários}

Nas questões abertas foram anotados os seguintes comentários dos respondentes:

\subsubsection{Formação}

Os entrevistados verbalizaram as seguintes afirmações sobre a formação:

"Muitos profissionais sentem dificuldades devido à falta de formação adequada para tratar a informação jurídica, ou nunca ter estudado Direito. Consideram difícil o início do trabalho com esse tipo de informação, por ser o Direito uma área muito complexa";

"O conhecimento da área jurídica é fundamental para um bom desempenho profissional nessa área. Alguns bibliotecários estão em busca de uma graduação em Direito adquirir conhecimentos mais específicos";

"Faltam cursos de pós-graduação voltados para os bibliotecários jurídicos, cursos de atualização / especialização e treinamentos em Brasília. 


\section{Atuação:}

Nas questões abertas foram coletadas as seguintes opiniões:

\section{Pontos positivos: facilidades}

"Há uma satisfação com a infra-estrutura disponível nos locais de trabalho";

\section{Pontos negativos: acomodação}

“A proximidade com o legislativo e a atração exercida pela remuneração oferecida causa certa acomodação no local de trabalho, já que sempre se espera conseguir passar em concurso para aquele setor";

"Há poucas propostas, entre os bibliotecários, para inovar os serviços e atividades que são de certa forma, incompatíveis com a infra-estrutura física e material disponível";

"Os bibliotecários devem contribuir para a melhoria das proposições apresentadas pelo legislativo, participando mais das discussões sobre o processo legislativo, antecipando pesquisas sobre projetos de lei em tramitação em outras unidades da federação".

"Precisam se tornar importantes para a instituição onde trabalham, antecipando-se com propostas, não apenas trabalhando para dar respostas às demandas apresentadas”;

\section{Problemas para a busca da informação}

"Para quem trabalha com legislação, é um desafio diário buscar informações atualizadas; a linguagem é muito rebuscada; a legislação sofre constantes alterações, falta ordenamento das leis, o que dificulta a recuperação";

"Nas pesquisas, o problema de encontrar informações em ambientes virtuais que nem sempre apresentam a autoria impossibilita a disseminação dessas informações aos usuários".

\section{Conclusão da análise dos resultados}

Com exceção do item "salário", conclui-se que alguns resultados alcançados são semelhantes aos resultados obtidos nos estudos de Tarapanoff (1997), Baptista (1998), Cunha et al. (2004), a saber: maioria do sexo feminino, as tarefas mais exercidas estão relacionadas com o ciclo documentário (recuperação da informação e catalogação) e poucos investimentos em educação continuada.

Especificamente, sobre a educação continuada, verificou-se que os bibliotecários da área jurídica têm dificuldades de dominar a linguagem / tipo de informação e, que os cursos oferecidos não estão adequados às demandas desse mercado. De acordo com a 
literatura da área, os bibliotecários fazem poucos investimentos em educação continuada. Na pesquisa de Baptista (1998, p.99) dos 1363 casos válidos, mais da metade não havia feito nenhum curso após a graduação.

Pretende-se, a partir dos dados levantados nesta pesquisa e ampliar esses questionamentos para outras regiões, procurando identificar similaridades ou diferenças entre os bibliotecários da área. Os Conselhos Regionais de Biblioteconomia poderiam adotar o sistema de realizar pesquisas similares para monitorar as questões profissionais da área.

\section{Referências}

AMARAL, Gilberto Luiz do; OLENIKE, João Eloi; STEINBRUCH, Fernando; AMARAL, Letícia Mary Fernandes do. Quantidade de normas editadas no Brasil: 18 anos da Constituição Federal de 1988. Curitiba: Instituto Brasileiro de Planejamento Tributário, 2004. Disponível em: <http://www.ibpt.com.br/arquivos/estudos/QUANTIDADE_DE_NORMAS__18_ANOS_DA_CF_1988.pdf>. Acesso em: 18 mar. 2007.

ANDERSON, Communications conflict at the law library reference desk: a survey of General Library Science Communications Literature. Library Reference Services Quartely, v.16, n. 4 , p.5-21, 1998.

BAPTISTA, Sofia Galvão. Bibliotecário autônomo versus institucionalizado: carreira, mercado de trabalho e comprometimento organizacional. 1998. $234 \mathrm{f}$. Tese (Doutor) - Curso de Doutorado em Ciência da Informação, Departamento de Ciência de Informação e Documentação, Universidade de Brasília, Brasília, 1998.

CRESPO, I. M. et al. Educação continuada para bibliotecários: características e perspectivas em um cenário de mudanças. Biblios, n.24-26, jul./dec. 2006 p. 8

CUNHA, M. F. V.; PEREIRA, M. C.; GUIMARAES, C.; SILVA, C. C. M. O bibliotecário formado pela Universidade Federal de Santa Catarina: perfil profissional. Perspectivas em Ciência da Informação, Belo Horizonte, v. 9, n. 2, 2004.

DIMÁRIO, Clélia J. K. et al. Formação continuada de bibliotecários e as ferramentas tecnológicas de educação à distância: uma proposta de intervenção educativa. Disponível em: <http://www.snbu2006.ufba.br/soac/viewpaper.php?id=> Acesso em: 24 maio 2007. 
GRANT, Virginia, ACOSTA, Luis. Principles governing compensation of law librarians. Report to legal management, 2004. Disponível em: < http://www.altmanweil.com/dir_docs/resource/7ad20fe2-5f27-46d9-8caed560e23e5f04 document.pdf >. Acesso em: 15 maio 2004.

LOUREIRO, Regina Célia Campagnoli. A especialidade do bibliotecário jurídico: bases para uma interação com o usuário operador do direito. [S.1.], 2005. Disponível em: $<$ http://www.infolegis.com.br/loureiro-especialidade.htm>. Acesso em: 30 abr. 2007

MIRANDA, Ana Cláudia Carvalho; SOLINO, Antonia da Silva. Educação continuada e mercado de trabalho: um estudo sobre os bibliotecários do estado do Rio Grande do Norte. Perspectivas da Ciência da Informação, Belo Horizonte, v. 11, n. 3, p. 383-397, set./dez. 2006.

MORIGI, V. J. ; PAVAN, Cleusa. Tecnologias de informação e comunicação: novas sociabilidades nas bibliotecas universitárias. Ciência da Informação, v. 33, n. 1, p. 117-125, 2004.

OHIRA, Maria Lourdes Blatt et al. Profissional da informação jurídica: três décadas de produção bibliográfica. IN: Anais do CIBERÉTICA e ENCONTRO NACIONAL DE INFORMAÇÃO E DOCUMENTAÇÃO JURIDICA, 6, Florianópolis, 1998. Disponível em: $>$ http://www.ciberetica.iaccess.com.br/portugues/main.htm>. Acesso em: [s.d].

PASSOS, Edilenice. Bibliotecário jurídico: seu perfil, seu papel. IN: ENCONTRO DE DOCUMENTAÇÃO E INFORMAÇÃO JURÍDICA DO RIO DE JANEIRO, 3., 2001, Rio de Janeiro. Anais__.Rio de Janeiro, 2001.

PASSOS, Edilenice. Bibliotecário jurídico: mapeamento de sua produção bibliográfica. IN: . Informação jurídica: teoria e prática. Brasília: Thesaurus, 2004. PASSOS, Edilenice. 237p. p. 189-200.

PAIVA, V. Qualificação, competências e empregabilidade no mundo pós-industrial. 2004. p.59. Disponível em: 〈http://168.96.200.17/ar/libros/educacion/paiva.pdf.〉. Acesso em: 2005.

PAULA, Sheila Farias de. O bibliotecário e sua atuação na área jurídica: a relevância da educação continuada no processo de atualização profissional. Campinas, 2005. Trabalho de conclusão de curso (Bacharel em Biblioteconomia).

SILVA, Fabiano Couto Correa. Bibliotecário especialista: guia de especialidades e recursos informacionais. Brasília: Thesaurus, 2005. p. 23-24. 
TARAPANOFF, Kira. O profissional da informação no Brasil. Brasília: IEL, 1997.

VALENTIM, Marta L. P. Formação: competências e habilidades do profissional da informação. IN: ___ Formação do profissional da informação. São Paulo: Polis, 2002 p. 


\section{APÊNDICE 1 - Questionário}

\section{UNIVERSIDADE DE BRASÍLIA}

Faculdade de Economia, Administração, Contabilidade e Ciência da Informação e Documentação Departamento de Ciência da Informação e Documentação.

Prezados Colegas,

Essa pesquisa que tem por objetivo identificar o perfil do bibliotecário que atua na área jurídica está sendo desenvolvida pela Profa. Dr ${ }^{a}$ Sofia Galvão Baptista (Departamento de Ciência da Informação e Documentação da Universidade de Brasília) e por Edilenice Passos (Mestre em Biblioteconomia e Documentação, pela Universidade de Brasília. Atualmente, é chefe do Serviço de Apoio Técnico da Consultoria Legislativa do Senado Federal).

Não é necessário se identificar. Envie sua resposta para o email: sofiag@unb.br. Os dados coletados serão apresentados no Seminário Nacional de Informação Jurídica (2007)

Agradecemos a colaboração.

\section{Informações gerais}

1.1) Indique sua faixa etária:

( ) 18 a $25 \operatorname{anos}$ ( ) 26 a 30 anos ( ) 31 a 35 anos ( ) 36 a 40 anos

( ) 41 a 45 anos ( ) 46 a 50 anos ( ) acima de 51 anos

1.2) Sexo: ( ) Feminino ( ) Masculino

1.3) Em qual unidade da Federação você reside e trabalha?

\section{Formação profissional}

2.1) Indique a universidade por onde se graduou em Biblioteconomia:...

2.2) Você possui outra graduação? ( ) Sim ( ) Não

2.2.1) Em caso afirmativo, indique qual: .

2.3) Você possui pós-graduação? ( ) Sim （ ）Não

2.3.1) Em caso afirmativo, indique qual:

2.4) Há quanto tempo você está formado?

( ) Menos de um ano ( ) De 1 a 3 anos ( ) De 4 a 6 anos ( ) De 7 a 10 ano ( ) Mais de 10 anos

\section{Ingresso / Preparação}

3.1) Indique a forma de ingresso no seu atual emprego:

( ) concurso ( ) entrevista ( ) outros:

3.2) Você freqüentou algum curso para adquirir conhecimentos específicos para atuar na área jurídica: ( ) Sim （ ) Não

3.2.1) Em caso afirmativo, indique o nome do curso e a entidade que o ofereceu:

3.3) Na sua opinião, quais são as dificuldades enfrentadas pelos bibliotecários jurídicos para atuarem na área: (assinale quantas opções forem necessárias): 
( ) falta de curso de especialização na área;

( ) dificuldade para entender a linguagem jurídica

( ) desconhecimento das fontes de informação jurídica

( ) falta de noções básicas sobre o Direito

( ) dificuldade para entender o processo legislativo

( ) desconhecimento de idiomas estrangeiros

( ) dificuldade para entender a organização judiciária

( ) dificuldade nas pesquisas em bases dados jurídicas

( ) falta de bases de dados que reúna a legislação estadual/ distrital/ municipal

( ) Outras. Especifique, por favor:

\section{Sobre o atual emprego}

4.1) Em que tipo de biblioteca trabalha?

( ) Do Poder Legislativo ( ) Do Poder Judiciário

( ) Do Poder Executivo ( ) Universitária ( ) De escritório de advocacia

( ) Outras. Especifique, por favor:

\subsection{Tarefas}

Quais são as tarefas que desempenha no seu atual emprego: (assinale quantas opções forem necessárias)

( ) pesquisa ( ) catalogação ( ) classificação

( ) desenvolvimento de coleções

( ) manutenção de websites/ homepages/ bibliotecas virtuais ou digitais

( ) serviço de disseminação seletiva da informação

( ) acompanhamento da legislação federal/ estadual/ municipal/ distrital

( ) acompanhamento da jurisprudência

( ) coleta e organização da normas jurídicas produzidas pela entidade onde trabalha

( ) Outras. Especifique, por favor:........

\subsection{Indique a sua faixa salarial:}

( ) menos de $\mathrm{R} \$ 1.000,00$ ( ) de $\mathrm{R} \$ 1.001,00$ a $\mathrm{R} \$ 2.000,00$

（ ) de $\mathrm{R} \$ 2.001,00$ a $\mathrm{R} \$ 3.000,00$ ( ) de $\mathrm{R} \$ 3.001,00$ a $\mathrm{R} \$ 4.000,00$

（ ） de $\mathrm{R} \$ 4.001,00$ a $\mathrm{R} \$ 5.000,00$ ( ) de $\mathrm{R} \$ 5.001,00$ a $\mathrm{R} \$ 6.000,00$

（ ) de $\mathrm{R} \$ 6.001,00$ a $\mathrm{R} \$ 7.000,00$ ( ) de $\mathrm{R} \$ 7.001,00$ a $\mathrm{R} \$ 8.000,00$

（ ） de $\mathrm{R} \$ 8.001,00$ a $\mathrm{R} \$ 9.000,00$ ( ) de $\mathrm{R} \$ 9.001,00$ a $\mathrm{R} \$ 10.000,00$

( ) acima de $\mathrm{R} \$ 10.000,00$

\section{Comentários gerais sobre essa área de atuação:}

174 Revista Ibero-americana de Ciência da Informação (RICI), v.1 n.2, p. 151-174, jul./dez. 2008 